\title{
Fixed Point Theorem for Cyclic Weakly Generalized Contraction Mapping of Ciric Type
}

\author{
S. Goyal ${ }^{1 *}$, M. Garg ${ }^{2}$ \\ ${ }^{1}$ Department of Mathematics, G.M.N. College, Ambala Cantt, Haryana, India \\ ${ }^{2}$ Department of Physics, A. S. College, Khanna, Punjab, India
}

Received 14 February 2020, accepted in final revised form 4 June 2020

\begin{abstract}
In this article, the concept of cyclic weakly generalized contraction mapping of Ciric type has been introduced and the existence of a fixed point for such mappings in the setup of complete metric spaces has been established. Result obtained extends and improves some fixed point results in the literature. Example is also given to show that class of contraction mappings introduced in the paper is strictly larger class than the class of mappings used in the literature and thus ensures wider applicability of the result by producing the solutions to new problems.
\end{abstract}

Keywords: Fixed point; Generalized contraction; Cyclic contraction.

(C) 2020 JSR Publications. ISSN: 2070-0237 (Print); 2070-0245 (Online). All rights reserved. doi: http://dx.doi.org/10.3329/jsr.v12i4.45501

J. Sci. Res. 12 (4), 463-471 (2020)

\section{Introduction}

It is well known that fixed point theorem of Banach is one of the main results of analysis. It is widely used in many fields of mathematics. Due to its importance, many authors have generalized this result in various directions [1-14]. Ciric [1] introduced the concept of generalized contractions.

Definition 1.1. Let $(\mathrm{X}, \mathrm{d})$ be a metric space. If $T: \mathrm{X} \rightarrow \mathrm{X}$ is such that for all $x, y \in X$, there exist non-negative real numbers $q(x, y), r(x, y), s(x, y)$ and $t(x, y)$ such that

$$
\sup _{x, y \in X}\{q(x, y)+r(x, y)+s(x, y)+2 t(x, y)\}=\lambda<1
$$

and

$d(T x, T y) \leq q(x, y) d(x, y)+r(x, y) d(x, T x)+s(x, y) d(y, T y)+t(x, y)(d(x, T y)+d(y, T x))$ holds for all $x, y \in X$ then $T$ is said to be a generalized contraction.

Ciric [1] proved that every generalized contraction in a complete metric space has a fixed point.

* Corresponding author: sujatagoyal184@gmail.com 
The class of generalized contractions include the Banach's contractions and the contractions introduced by Kannan [3] and Chatterjea [4]. Alber and Guerre-Delabriere [6] introduced the concept of weakly contractive type mapping and proved the existence of fixed point for such mappings in Hilbert Spaces. Weakly contractive mappings include contractions as a special case. Many fixed point results were proved using the concept of weakly contractions [3-13]. Kirk et al. [2] introduced the concept of cyclic contractions.

Definition 1.2: [2] Let $X$ be a nonempty set and $T: X \rightarrow X$ be a map.

a) $X=\bigcup_{i=1}^{m} A_{i}$ where $A_{i}, i=1,2, \ldots . m$ are nonempty subsets of $\mathrm{X}$.

b) $T\left(A_{1}\right) \subseteq A_{2}, T\left(A_{2}\right) \subseteq A_{3}, \ldots . . T\left(A_{m-1}\right) \subseteq A_{m}, T\left(A_{m}\right) \subseteq A_{1}$.

c) $\exists k \in(0,1)$ э $d(T x, T y) \leq k d(x, y)$ for any $x \in A_{i}, y \in A_{i+1}, i=1,2, \ldots m$ where $A_{m+1}=A_{1}$.

In this case $T$ is said to be cyclic contraction.

Karapinar et al. [5] introduced generalized cyclic weakly Chatterjea type contractions.

Definition 1.3: [5] Let $(X, d)$ be a metric space and $\mathrm{m}$ be a natural number. $A_{i}, i=1,2, \ldots . . m$ be nonempty subsets of $X$ and $Y=\bigcup_{i=1}^{m} A_{i}$. An operator $T: Y \rightarrow Y$ is called a generalized cyclic weakly Chatterjea type contraction if

(a) $Y=\bigcup_{i=1}^{m} A_{i}$ is a cyclic representation of $Y$ with respect to $T$.

(b) For any $x \in A_{i}, y \in A_{i+1}, i=1,2, \ldots m$,

$$
\begin{aligned}
d(T x, T y) \leq & \alpha[d(x, T x)+d(y, T y)+d(x, T y)+d(y, T x)] \\
& -\psi(d(x, T x), d(y, T y), d(x, T y), d(y, T x)),
\end{aligned}
$$

Where $A_{m+1}=A_{1}$ and $\psi:[0, \infty)^{4} \rightarrow[0, \infty)$ is lower semi-continuous map satisfying $\psi\left(t_{1}, t_{2}, t_{3}, t_{4}\right)=0$ if $t_{1}=t_{2}=t_{3}=t_{4}=0$ and $\alpha \in(0,1 / 4)$.

Karapinar et al. [5] proved the following theorem.

Theorem 1.4: [5] Let $(X, d)$ be a complete metric space and $\mathrm{m}$ be a natural number. $A_{i}, i=1,2, \ldots . . m$ be nonempty subsets of $X$ and $Y=\bigcup_{i=1}^{m} A_{i}$. Suppose that $T$ is a generalized cyclic weakly Chatterjea type contractions then $T$ has a unique fixed point $x \in \bigcap_{i=1}^{m} A_{i}$.

In this paper, cyclic weakly generalized contraction mappings of Ciric type have been introduced and the existence of fixed point for such maps has been proved. Example is also given to show that our result is a generalization of the result in Karapinar et al. [5]. 


\section{Main Results}

The concept of cyclic weakly generalized contractions of Ciric type has been introduced and a fixed point result for such contractions in the framework of complete metric space has been derived.

Let $\Phi$ denote all monotonically increasing continuous functions $\mu:[0, \infty) \rightarrow[0, \infty)$ with $\mu(t)=0$ if $t=0$ and $\Psi$ denote the set of all lower semi-continuous maps $\psi:[0, \infty)^{5} \rightarrow[0, \infty)$ with $\psi\left(t_{1}, t_{2}, t_{3}, t_{4}, t_{5}\right)=0$ if $t_{1}=t_{2}=t_{3}=t_{4}=t_{5}=0$.

Definition 2.1: Let $(\mathrm{X}, \mathrm{d})$ be a metric space and $m$ be a natural number, $A_{1}, A_{2} \ldots . A_{m}$ nonempty subsets of $X$ and $Y=\bigcup_{i=1}^{m} A_{i}$ is such that for all $x, y \in X$, there exist non negative real numbers $q(x, y), r(x, y), s(x, y)$ and $t(x, y)$ such that

$$
\begin{gathered}
\sup _{x, y \in X}\{q(x, y)+r(x, y)+s(x, y)+2 t(x, y)\}=\lambda<1, \\
\mu(d(T x, T y)) \leq \mu(q(x, y) d(x, y)+r(x, y) d(x, T x)+s(x, y) d(y, T y)+t(x, y)(d(x, T y)+d(y, T x))) \\
-\psi(d(x, y), d(x, T x), d(y, T y), d(x, T y,), d(y, T x))
\end{gathered}
$$

for any $x \in A_{i}, y \in A_{i+1}, i=1,2, \ldots m$ where $A_{m+1}=A_{1}, \mu \in \Phi$ and $\psi \in \Psi$.

Then $T$ is said to be a cyclic weakly generalized contraction mapping of Ciric type.

Theorem 2.2: Let $(X, d)$ be a complete metric space, $\mathrm{m}$ be a natural number, $A_{1}, A_{2} \ldots . A_{m}$ be nonempty closed subsets of $X$ and $Y=\bigcup_{i=1}^{m} A_{i}$. Suppose that $T: Y \rightarrow Y$ is a cyclic weakly generalized contraction mapping of Ciric type. Then $T$ has a unique fixed point $x \in \bigcap_{i=1}^{m} A_{i}$.

Proof: Let $x_{0} \in X$.Define a sequence $\left(x_{n}\right)$ in $X$ as $x_{n+1}=T x_{n}, n=0,1,2 \ldots$

If for any $n, x_{n+1}=x_{n}$ then $x_{n}$ will be the fixed point and hence the result. Therefore, it is assumed that $x_{n+1} \neq x_{n}$ for any $n=0,1,2 \ldots$

As $Y=\bigcup_{i=1}^{m} A_{i}$, therefore for any $n>0$, there exists $i_{n} \in\{1,2, \ldots m\}$ such that $x_{n-1} \in A_{i_{n}}$ and $x_{n} \in A_{i_{n}+1}$.

By definition 2.1 we have,

$$
\begin{aligned}
\mu\left(d\left(x_{n+1}, x_{n}\right)=\mu(\right. & \left.d\left(T x_{n}, T x_{n-1}\right)\right) \leq \mu\left(q\left(x_{n}, x_{n-1}\right) d\left(x_{n}, x_{n-1}\right)+r\left(x_{n}, x_{n-1}\right) d\left(x_{n}, T x_{n}\right)\right. \\
& \left.+s\left(x_{n}, x_{n-1}\right) d\left(x_{n-1}, T x_{n-1}\right)+t\left(x_{n}, x_{n-1}\right)\left(d\left(x_{n}, T x_{n-1}\right)+d\left(x_{n-1}, T x_{n}\right)\right)\right) \\
& -\psi\left(d\left(x_{n}, x_{n-1}\right), d\left(x_{n}, T x_{n}\right), d\left(x_{n-1}, T x_{n-1}\right), d\left(x_{n}, T x_{n-1}\right), d\left(x_{n-1}, T x_{n}\right)\right) \\
\leq & \mu\left(q\left(x_{n}, x_{n-1}\right) d\left(x_{n}, x_{n-1}\right)+r\left(x_{n}, x_{n-1}\right) d\left(x_{n}, T x_{n}\right)\right. \\
& \left.+s\left(x_{n}, x_{n-1}\right) d\left(x_{n-1}, T x_{n-1}\right)+t\left(x_{n}, x_{n-1}\right)\left(d\left(x_{n}, T x_{n-1}\right)+d\left(x_{n-1}, T x_{n}\right)\right)\right) .
\end{aligned}
$$


Since $\mu$ is monotonically increasing function, for all $n=1,2, \ldots$, therefore ,

Consequently

$$
\begin{aligned}
d\left(x_{n+1}, x_{n}\right) & \leq q\left(x_{n}, x_{n-1}\right) d\left(x_{n}, x_{n-1}\right)+r\left(x_{n}, x_{n-1}\right) d\left(x_{n}, x_{n+1}\right) \\
& +s\left(x_{n}, x_{n-1}\right) d\left(x_{n-1}, x_{n}\right)+t\left(x_{n}, x_{n-1}\right)\left(d\left(x_{n}, x_{n}\right)+d\left(x_{n-1}, x_{n+1}\right)\right) \\
& \leq q\left(x_{n}, x_{n-1}\right) d\left(x_{n}, x_{n-1}\right)+r\left(x_{n}, x_{n-1}\right) d\left(x_{n}, x_{n+1}\right) \\
& +s\left(x_{n}, x_{n-1}\right) d\left(x_{n-1}, x_{n}\right)+t\left(x_{n}, x_{n-1}\right)\left(d\left(x_{n-1}, x_{n}\right)+d\left(x_{n}, x_{n+1}\right)\right) .
\end{aligned}
$$

$d\left(x_{n+1}, x_{n}\right)\left[1-r\left(x_{n}, x_{n-1}\right)-t\left(x_{n}, x_{n-1}\right)\right] \leq d\left(x_{n}, x_{n-1}\right)\left(q\left(x_{n}, x_{n-1}\right)+s\left(x_{n}, x_{n-1}\right)+t\left(x_{n}, x_{n-1}\right)\right)$.

Since $\lambda<1$, from $q\left(x_{n}, x_{n-1}\right)+r\left(x_{n}, x_{n-1}\right)+s\left(x_{n}, x_{n-1}\right)+2 t\left(x_{n}, x_{n-1}\right) \leq \lambda$,

Therefore,

$$
\begin{aligned}
q\left(x_{n}, x_{n-1}\right)+s\left(x_{n}, x_{n-1}\right)+t\left(x_{n}, x_{n-1}\right) & \leq \lambda-r\left(x_{n}, x_{n-1}\right)-t\left(x_{n}, x_{n-1}\right) \\
& \leq \lambda-\lambda r\left(x_{n}, x_{n-1}\right)-\lambda t\left(x_{n}, x_{n-1}\right) .
\end{aligned}
$$

Which implies that

$$
\frac{q\left(x_{n-1}, x_{n}\right)+s\left(x_{n-1}, x_{n}\right)+t\left(x_{n-1}, x_{n}\right)}{1-r\left(x_{n-1}, x_{n}\right)-t\left(x_{n-1}, x_{n}\right)} \leq \lambda .
$$

Thus from (2.1.1) it follows $d\left(x_{n+1}, x_{n}\right) \leq \lambda d\left(x_{n}, x_{n-1}\right)$.

Repeating the above procedure $n$ times,

$$
d\left(x_{n+1}, x_{n}\right) \leq \lambda d\left(x_{n}, x_{n-1}\right) \leq \lambda^{2} d\left(x_{n-1}, x_{n-2}\right) \leq \lambda^{n} d\left(x_{1}, x_{0}\right) .
$$

From (2.1.2), it follows that

$$
d\left(x_{n+1}, x_{n}\right) \rightarrow 0 \text { as } n \rightarrow \infty
$$

Now the sequence $\left(x_{n}\right)$ will be proved to be a Cauchy sequence. For this purpose, we prove the following claim:

For every $\in>0$, there exists a natural no. $n$ such that if $r, q \geq n$ with $r-q \equiv 1(\bmod m)$, then $d\left(x_{r}, x_{q}\right)<\in$.

On contrary suppose there exists $\in>0$ such that for any $n \in N$, we can find $r_{n}, q_{n} \geq n$ with $r_{n}-q_{n} \equiv 1(\bmod m)$ satisfying $d\left(x_{r_{n}}, x_{q_{n}}\right) \geq \epsilon$.

Now take $n>2 m$. Then, corresponding to $q_{n} \geq n$, choose $r_{n}$ such that it is the smallest integer with $r_{n}>q_{n}$ satisfying $r_{n}-q_{n} \equiv 1(\bmod m)$ and $d\left(x_{r_{n}}, x_{q_{n}}\right) \geq \in$.

Thus $d\left(x_{r_{n}-m}, x_{q_{n}}\right)<\in$.

By using the triangular inequality,

$$
\in \leq d\left(x_{q_{n}}, x_{r_{n}}\right) \leq d\left(x_{q_{n}}, x_{r_{n}-m}\right)+\sum_{i=1}^{m} d\left(x_{r_{n}-i}, x_{r_{n}-i+1}\right)<\in+\sum_{i=1}^{m} d\left(x_{r_{n}-i}, x_{r_{n}-i+1}\right) .
$$

Letting $n \rightarrow \infty$ and using $d\left(x_{n+1}, x_{n}\right) \rightarrow 0$,

$$
\underset{n \rightarrow \infty}{\operatorname{Lt}} d\left(x_{q_{n}}, x_{r_{n}}\right)=\in \text {. }
$$


Again, by triangular inequality,

$$
\begin{array}{r}
\in \leq d\left(x_{q_{n}}, x_{r_{n}}\right) \leq d\left(x_{q_{n}}, x_{q_{n}+1}\right)+d\left(x_{q_{n}+1}, x_{r_{n}+1}\right)+d\left(x_{r_{n}+1}, x_{r_{n}}\right) \\
\leq 2 d\left(x_{q_{n}}, x_{q_{n}+1}\right)+d\left(x_{q_{n}}, x_{r_{n}}\right)+2 d\left(x_{r_{n}}, x_{r_{n}+1}\right) .
\end{array}
$$

Letting $n \rightarrow \infty$ and using $d\left(x_{n+1}, x_{n}\right) \rightarrow 0$,

$$
\operatorname{Lt}_{n \rightarrow \infty} d\left(x_{q_{n}+1}, x_{r_{n}+1}\right)=\in \text {. }
$$

Consider

$$
\begin{aligned}
d\left(x_{q_{n}}, T x_{r_{n}}\right) & =d\left(x_{q_{n}}, x_{r_{n}+1}\right) \\
& \leq d\left(x_{q_{n}}, x_{r_{n}}\right)+d\left(x_{r_{n}}, x_{r_{n}+1}\right)
\end{aligned}
$$

and

$d\left(x_{q_{n}}, x_{r_{n}+1}\right)+d\left(x_{r_{n}+1}, x_{r_{n}}\right) \geq d\left(x_{q_{n}}, x_{r_{n}}\right)$.

Taking limit $n \rightarrow \infty$,

$$
\operatorname{Lt}_{n \rightarrow \infty} d\left(x_{q_{n}}, x_{r_{n}}\right)=\in \text {. }
$$

Consider

$$
\begin{aligned}
d\left(x_{r_{n}}, T x_{q_{n}}\right)= & d\left(x_{r_{n}}, x_{q_{n+1}}\right) \\
& \leq d\left(x_{r_{n}}, x_{q_{n}}\right)+d\left(x_{q_{n}}, x_{q_{n+1}}\right)
\end{aligned}
$$

and

$d\left(x_{r_{n}}, x_{q_{n}+1}\right)+d\left(x_{q_{n}+1}, x_{q_{n}}\right) \geq d\left(x_{q_{n}}, x_{r_{n}}\right)$.

Taking limit $n \rightarrow \infty$,

$$
\underset{n \rightarrow \infty}{\operatorname{Lt}} d\left(x_{r_{n}}, T x_{q_{n}}\right)=\in \text {. }
$$

Now as $x_{q_{n}}$ and $x_{r_{n}}$ lie in different adjacent set $A_{i}$ and $A_{i+1}$ for certain $1 \leq i \leq m$, using the fact that $T$ is a cyclic weakly generalized contraction mapping of Ciric type,

$$
\begin{aligned}
\mu(\in) \leq & \mu\left(d\left(x_{q_{n}+1}, x_{r_{n}+1}\right)\right. \\
= & \mu\left(d\left(T x_{q_{n}}, T x_{r_{n}}\right)\right. \\
\leq & \mu\left(q\left(x_{q_{n}}, x_{r_{n}}\right) d\left(x_{q_{n}}, x_{r_{n}}\right)+r\left(x_{q_{n}}, x_{r_{n}}\right) d\left(x_{q_{n}}, T x_{q_{n}}\right)\right. \\
& +s\left(x_{q_{n}}, x_{r_{n}}\right) d\left(x_{r_{n}}, T x_{r_{n}}\right)+t\left(x_{q_{n}}, x_{r_{n}}\right)\left(d\left(x_{q_{n}}, T x_{r_{n}}\right)+d\left(x_{r_{n}}, T x_{q_{n}}\right)\right) \\
& -\psi\left(d\left(x_{q_{n}}, x_{r_{n}}\right), d\left(x_{q_{n}}, T x_{q_{n}}\right), d\left(x_{r_{n}}, T x_{r_{n}}\right), d\left(x_{q_{n}}, T x_{r_{n}}\right), d\left(x_{r_{n}}, T x_{q_{n}}\right)\right) \\
& =\mu\left(q\left(x_{q_{n}}, x_{r_{n}}\right) d\left(x_{q_{n}}, x_{r_{n}}\right)+r\left(x_{q_{n}}, x_{r_{n}}\right) d\left(x_{q_{n}}, x_{q_{n}+1}\right)\right. \\
& \left.+s\left(x_{q_{n}}, x_{r_{n}}\right) d\left(x_{r_{n}}, x_{r_{n}+1}\right)+t\left(x_{q_{n}}, x_{r_{n}}\right)\left(d\left(x_{q_{n}}, x_{r_{n}+1}\right)+d\left(x_{r_{n}}, x_{q_{n}+1}\right)\right)\right) \\
& \quad-\psi\left(d\left(x_{q_{n}}, x_{r_{n}}\right), d\left(x_{q_{n}}, x_{q_{n}+1}\right), d\left(x_{r_{n}}, x_{r_{n}+1}\right), d\left(x_{q_{n}}, x_{r_{n}+1}\right), d\left(x_{r_{n}}, x_{q_{n}+1}\right)\right) .
\end{aligned}
$$

Taking limit superior both sides in (2.1.8), using (2.1.3), (2.1.4-2.1.7), continuity of $\mu$ and lower semi continuity of $\psi$, 


$$
\begin{aligned}
& \mu(\in) \leq \varlimsup \lim \mu\left(q\left(x_{q_{n}}, x_{r_{n}}\right) d\left(x_{q_{n}}, x_{r_{n}}\right)+r\left(x_{q_{n}}, x_{r_{n}}\right) d\left(x_{q_{n}}, x_{q_{n}+1}\right)\right. \\
& \left.+s\left(x_{q_{n}}, x_{r_{n}}\right) d\left(x_{r_{n}}, x_{r_{n}+1}\right)+t\left(x_{q_{n}}, x_{r_{n}}\right)\left(d\left(x_{q_{n}}, x_{r_{n}+1}\right)+d\left(x_{r_{n}}, x_{q_{n}+1}\right)\right)\right) \\
& -\psi\left(d\left(x_{q_{n}}, x_{r_{n}}\right), d\left(x_{q_{n}}, x_{q_{n}+1}\right), d\left(x_{r_{n}}, x_{r_{n}+1}\right), d\left(x_{q_{n}}, x_{r_{n}+1}\right), d\left(x_{r_{n}}, x_{q_{n}+1}\right)\right) \\
& =\mu\left(\varlimsup \left(\lim q\left(x_{q_{n}}, x_{r_{n}}\right)(\in)+\varlimsup \lim r\left(x_{q_{n}}, x_{r_{n}}\right)(0)+\varlimsup \lim s\left(x_{q_{n}}, x_{r_{n}}\right)(0)\right.\right. \\
& \left.+\varlimsup t\left(x_{q_{n}}, x_{r_{n}}\right)(\in+\in)\right)-\psi(\in, 0,0, \in, \in) \\
& \left.=\mu\left(\in\left(\varlimsup \lim q\left(x_{q_{n}}, x_{r_{n}}\right)\right)+\varlimsup \lim 2 t\left(x_{q_{n}}, x_{r_{n}}\right)\right)\right)-\psi(\in, 0,0, \in, \in) \\
& \leq \mu(\in)-\psi(\in, 0,0, \in, \in) \text {. }
\end{aligned}
$$

Consequently $\psi(\in, 0,0, \in, \in) \leq 0$

which is a contradiction with $\in>0$.

Hence the claim is proved.

Now the sequence $\left(x_{n}\right)$ will be proved to be Cauchy

Let $\in>0$ be given.

By previous lemma, we can find $n_{0} \in \mathrm{N}$ such that $r, q \geq n_{0}$ with $r-q \equiv 1(\bmod m)$

$d\left(x_{r}, x_{q}\right) \leq \in / 2$.

Since

$\underset{n \rightarrow \infty}{L t} d\left(x_{n}, x_{n+1}\right)=0$,

Therefore, there exists $n_{1} \in \mathrm{N}$ such that

$d\left(x_{n}, x_{n+1}\right) \leq \in / 2 m$ for any $n \geq n_{1}$.

Assume that $r, s \geq \max \left\{n_{0}, n_{1}\right\}$ and $s>r$

Then there exists $k \in\{1,2, \ldots, m\}$ such that

$s-r \equiv k(\bmod m)$.

Hence $s-r+j \equiv 1(\bmod m)$ where $j=m-k+1$.

Thus we have

$d\left(x_{r}, x_{s}\right) \leq d\left(x_{r}, x_{s+j}\right)+d\left(x_{s+j}, x_{s+j-1}\right)+\ldots+d\left(x_{s+1}, x_{s}\right)$.

Using (2.1.9) and (2.1.10) in eq. (2.1.11),

$$
d\left(x_{r}, x_{s}\right) \leq \frac{\epsilon}{2}+j \frac{\epsilon}{2 m} \leq \frac{\epsilon}{2}+m \frac{\epsilon}{2 m}=\epsilon .
$$

Hence $\left(x_{n}\right)$ is Cauchy sequence in $Y$.

Since $Y$ is closed in $X$. Therefore $Y$ is also complete and there exists $x \in Y$ such that $\operatorname{Lt}_{n \rightarrow \infty} x_{n}=x$.

As $Y=\bigcup_{i=1}^{m} A_{i}$ is cyclic representation of $Y$ with respect to $T$, the sequence $\left(x_{n}\right)$ has infinite terms in each $A_{i}$ for $i \in\{1,2, \ldots, m\}$. Suppose that $x \in A_{i}, T x \in A_{i+1}$ and a subsequence $\left(x_{n_{k}}\right)$ of $\left(x_{n}\right)$ with $x_{n_{k}} \in A_{i}$ can be taken.

By using the contractive condition, 


$$
\begin{aligned}
\mu\left(d\left(x_{n_{k}+1}, T x\right)\right. & =\mu\left(d\left(T x_{n_{k}}, T x\right)\right. \\
& \leq \mu\left(q\left(x_{n_{k}}, x\right) d\left(x_{n_{k}}, x\right)+r\left(x_{n_{k}}, x\right) d\left(x_{n_{k}}, x_{n_{k}+1}\right)\right. \\
& +s\left(x_{n_{k}}, x\right) d(x, T x)+t\left(x_{n_{k}}, x\right)\left[d\left(x_{n_{k}}, T x\right)+d\left(x_{n_{k}+1}, x\right)\right) \\
& -\psi\left(d\left(x_{n_{k}}, x\right), d\left(x_{n_{k}}, x_{n+1}\right), d(x, T x), d\left(x_{n_{k}}, T x\right), d\left(x_{n_{k}+1}, x\right)\right) .
\end{aligned}
$$

Taking limit superior both sides and using continuity of $\mu$ and lower semi continuity of $\psi$,

$$
\begin{gathered}
\mu\left(d(x, T x) \leq \mu\left(\varlimsup \lim q\left(x_{n_{k}}, x\right)(0)+\varlimsup \lim r\left(x_{n_{k}}, x\right)(0)\right.\right. \\
\left.+\varlimsup \varlimsup i m s\left(x_{n_{k}}, x\right) d(x, T x)+\varlimsup \lim t\left(x_{n_{k}}, x\right)(d(x, T x)+0)\right) \\
-\psi(0,0, d(x, T x), d(x, T x), 0) \\
=\mu(d(x, T x)(\varlimsup \\
-\psi(0,0, d(x, T x), d(x, T x), 0) \\
\leq \mu(d(x, T x))-\psi(0,0, d(x, T x), d(x, T x), 0) .
\end{gathered}
$$

Which is a contradiction unless $d(x, T x)=0$.

Hence $x$ is a fixed point of $T$.

Since $x \in A_{i}$ and $T x=x \in A_{i+1} \Rightarrow x \in A_{i}$ for all $i=1,2, \ldots m$ i.e. $x \in \bigcap_{i=1}^{m} A_{i}$.

Now we prove the uniqueness of fixed point.

Suppose $x_{1}$ and $x_{2}$ are two fixed points of $T$.

Using the contractive condition, the continuity of $\mu$ and lower semi continuity of $\psi$,

$$
\begin{aligned}
\mu\left(d\left(x_{1}, x_{2}\right)=\right. & \mu\left(d\left(T x_{1}, T x_{2}\right)\right. \\
\leq & \mu\left(q\left(x_{1}, x_{2}\right) d\left(x_{1}, x_{2}\right)+r\left(x_{1}, x_{2}\right) d\left(x_{1}, T x_{1}\right)\right. \\
& \left.+s\left(x_{1}, x_{2}\right) d\left(x_{2}, T x_{2}\right)+t\left(x_{1}, x_{2}\right)\left(d\left(x_{1}, T x_{2}\right)+d\left(x_{2}, T x_{1}\right)\right)\right) \\
- & \psi\left(d\left(x_{1}, x_{2}\right), d\left(x_{1}, T x_{1}\right), d\left(x_{2}, T x_{2}\right), d\left(x_{1}, T x_{2}\right), d\left(x_{2}, T x_{1}\right)\right) \\
= & \mu\left(q\left(x_{1}, x_{2}\right) d\left(x_{1}, x_{2}\right)+2 t\left(x_{1}, x_{2}\right) d\left(x_{1}, x_{2}\right)\right) \\
& -\psi\left(d\left(x_{1}, x_{2}\right), 0,0, d\left(x_{1}, x_{2}\right), d\left(x_{2}, x_{1}\right)\right) \\
\leq & \mu\left(d\left(x_{1}, x_{2}\right)-\psi\left(d\left(x_{1}, x_{2}\right), 0,0, d\left(x_{1}, x_{2}\right), d\left(x_{2}, x_{1}\right)\right) .\right.
\end{aligned}
$$

Which is a contradiction unless $x_{1}=x_{2}$.

Hence the main result is proved

Now consider the following example,

Example 2.3: Let $X$ be the space of real numbers with usual metric.

Suppose $A_{1}=[-10,0], A_{2}=[0,10]$ and $Y=A_{1} \cup A_{2}$ Define $T: Y \rightarrow Y$ as $T x=\frac{-3}{4} x$ then it is clear that $\bigcup_{i=1}^{2} A_{i}$ is cyclic representation of $Y$ with respect to $T$. Then $T$ is not a generalized cyclic weakly Chatterjea type contraction because otherwise $T$ would satisfy 


$$
\begin{gathered}
\left|\frac{-3}{4} x+\frac{3}{4} y\right| \leq \alpha\left(\left|x+\frac{3}{4} x\right|+\left|y+\frac{3}{4} y\right|+\left|x+\frac{3}{4} y\right|+\left|y+\frac{3}{4} x\right|\right) \\
-\psi\left(\left|x+\frac{3}{4} x\right|,\left|y+\frac{3}{4} y\right|,\left|x+\frac{3}{4} y\right|,\left|y+\frac{3}{4} x\right|\right)
\end{gathered}
$$

for all $x \in A_{i}, y \in A_{i+1}$ for some $0 \leq \alpha<1 / 4$.

But $x=-8, y=8$ do not satisfy above inequality.

Now we see that is $T$ cyclic weakly generalized contraction of Ciric type.

Define $\psi:[0, \infty)^{5} \rightarrow[0, \infty)$ as

$$
\begin{aligned}
\psi(x, y, z, t, w)= & \frac{1}{40}(x+y+z+t+w) \\
d(T x, T y)=\left|\frac{-3}{4} x+\frac{3}{4} y\right| & =\frac{3}{4}|x-y| \\
\leq & q(x, y) d(x, y)+r(x, y) d(x, T x)+s(x, y) d(y, T y)+t(x, y)(d(x, T y)+d(y, T x)) \\
& -\psi\{d(x, y), d(x, T x), d(y, T y), d(x, T y,), d(y, T x)\} \\
= & q(x, y)|x-y|+r(x, y)\left|x+\frac{3}{4} x\right|+s(x, y)\left|y+\frac{3}{4} y\right|+t(x, y) \mid\left(\left|x+\frac{3}{4} y\right|+\left|y+\frac{3}{4} x\right|\right) \\
& -\frac{1}{40}\left(|x-y|+\left|x+\frac{3}{4} x\right|+\left|y+\frac{3}{4} y\right|+\left|x+\frac{3}{4} y\right|+\left|y+\frac{3}{4} x\right|\right) \\
= & \left(q(x, y)-\frac{1}{40}\right)|x-y|+\left(r(x, y)-\frac{1}{40}\right)\left|x+\frac{3}{4} x\right|+\left(s(x, y)-\frac{1}{40}\right)\left|y+\frac{3}{4} y\right| \\
& \quad+\left(t(x, y)-\frac{1}{40}\right)\left(\left|x+\frac{3}{4} y\right|+\left|y+\frac{3}{4} x\right|\right) .
\end{aligned}
$$

Taking $q(x, y)=\frac{31}{40}, r(x, y)=\frac{1}{40}, s(x, y)=\frac{1}{40}, t(x, y)=\frac{1}{40} \quad$ in $(2.3 .1)$,

we get

$\frac{3}{4}|x-y| \leq \frac{3}{4}|x-y|$,

which is true. Hence $T$ is cyclic weakly generalized contraction of Ciric type.

However, it is obvious that every generalized cyclic weakly Chatterjea type contraction is cyclic weakly generalized contraction of Ciric type. Thus the class of cyclic weakly generalized contraction of Ciric type is actually a strictly larger class of mappings than the class of generalized cyclic weakly Chatterjea type contraction.

\section{Conclusion}

In this paper, we introduced cyclic weakly generalized contraction mapping of Ciric type and presented fixed point for such mapping in complete metric spaces. We gave an 
example to show that the class of these contraction mappings is strictly larger than the class of generalized cyclic weakly Chatterjea type contractions. Results obtained in this paper can be expanded. Also, a new more general condition can be achieved. There is also possibility of extending the results to other spaces.

\section{References}

1. L. B. Ciric, Publ. Inst. Math. 12, 19 (1971).

2. W. A. Kirk, P. S. Srinivasan, and P. Veeramani, Fixed Point Theory 4, 79 (2003). https://doi.org/10.1155/S1085337503209064

3. R. Kannan, Bull. Cal. Math. Soc. 60, 71 (1968).

4. S. K. Chatterjea, C. R. Acad. Bulgare Sci. 25, 727 (1972).

5. E. Karapinar and H. K. Nashine, J. Appl. Math. 2012, ID 107 (2012). https://doi.org/10.1186/1687-1812-2012-107

6. Y. I. Alber and S. G. Delabriere, New Results in Operator Theory Its Applications, in Operator Theory: Advances and Applications (Springer, Switzerland, 1997) vol. 98, pp. 7-22. https://doi.org/10.1007/978-3-0348-8910-0_2

7. B. E. Rhoades, Nonlinear Analysis: Theory, Methods Applicat. 47, 2683 (2001). https://doi.org/10.1016/S0362-546X(01)00388-1

8. S. Reich, Matematiche e Naturali. Rendiconti. 57, 194 (1974).

9. S. Chandok, J. Appl. Math. 29, 257 (2011). https://doi.org/10.1007/s00350-011-2889-0

10. S. Chandok, T. D. Narang, and M. A. Taoudi, Vietnam J. Math. 41, 323 (2013). https://doi.org/10.1007/s10013-013-0024-4

11. S. Chandok and M. Postolache, Fixed Point Theory Appl. 28, 1 (2013). https://doi.org/10.1186/1687-1812-2013-28

12. S. Cho, Fixed Point Theory Appl. 2018, ID 3 (2018). https://doi.org/10.1186/s13663-018-06281

13. Z. Xue, B Aust. Math. Soc. 93, 321 (2016). https://doi.org/10.1017/S0004972715001069

14. B. Vijayabaskerreddy and V. Srinivas, J. Sci. Res. 12, 341 (2020). https://doi.org/10.3329/jsr.v12i3.44754 